\title{
ESTUDO COMPARATIVO DA ATIVIDADE ANTIBACTERIANA DE EXTRATOS VEGETAIS DE Senna spectabilis, Rosmarinus officinalis E Eugenia uniflora FRENTE À CEPA PADRÃO DE Pseudomonas aeruginosa ATCC 27853, Staphylococcus aureus ATCC 6538 E Streptococcus pyogenes ATCC 19615
}

\author{
Vinicius Pereira Arantes ${ }^{1}$ \\ Lays Fernandes dos Santos $^{2}$ \\ Karen da Silva Diniz ${ }^{2}$ \\ Gabriela Oliveira da Silva ${ }^{2}$ \\ Gustavo Meireles Costa ${ }^{3}$
}

\begin{abstract}
ARANTES, V. P.; SANTOS, L. F. dos; DINIZ, K. da S.; SILVA, G. O. da; COSTA, G. M. Estudo comparativo da atividade antibacteriana de extratos vegetais de Senna spectabilis, Rosmarinus officinalis e Eugenia uniflora frente à cepa padrão de Pseudomonas aeruginosa ATCC 27853, Staphylococcus aureus ATCC 6538 e Streptococcus pyogenes ATCC 19615. Arq. Cienc. Saúde UNIPAR, Umuarama, v. 20, n. 3, p, 151-158, set./dez. 2016.
\end{abstract}

\begin{abstract}
RESUMO: O interesse em terapias alternativas e o uso terapêutico por derivados de plantas vêm crescendo nos últimos anos, obtendo um grande avanço científico no aspecto químico e farmacológico, a Organização Mundial da Saúde (OMS), considera as plantas medicinais como importantes instrumentos da assistência farmacêutica. Objetivo: Determinar atividade antibacteriana comparada entre os extratos de Senna spectabilis, Rosmarinus officinalis e Eugenia uniflora frente à cepa padrão de Pseudomonas aeruginosa ATCC 27853, Staphylococcus aureus ATCC 6538 e Streptococcus pyogenes ATCC 19615. As folhas de E. uniflora, R. officinallis e S. spectabilis foram coletadas no Horto de plantas medicinais da Universidade Estadual de Maringá - UEM/PR e as cepas foram fornecidas pela Universidade Paranaense - Unipar. A atividade antibacteriana foi determinada por meio da técnica do microdiluição em placa, empregando revelador de crescimento Alamar Blue Assay (MABA). A concentração mínima inibitória (CIM) empregando R. officinalis, E. uniflora, frente a cepa de $S$. aureus ATCC pode revelar resultados de $125 \mu \mathrm{g} / \mathrm{mL}$, para extratos de $S$. spectabilis o CIM foi de $250 \mu \mathrm{g} / \mathrm{mL}$; para $S$. pyogenes o CIM de 125 $\mu \mathrm{g} / \mathrm{mL}$ foi admitido apenas para $R$. officinalis e $S$. spectabilis, E. uniflora apresentou resultados de $500 \mu \mathrm{g} / \mathrm{mL}$, para $P$. aeruginosa o CIM para os três extratos foi superior a $500 \mu \mathrm{g} / \mathrm{mL}$. Os extratos são promissores quando empregados contra $S$. aureus e $S$. pyogenes, exceto para P. aeruginosa, no entanto cabe buscar novas alternativas para tratamento deste Gram-negativo.
\end{abstract}

PALAVRAS-CHAVE: Antibacteriano. Extratos vegetais. Resistência.

COMPARATIVE STUDY ON THE ACTIVITY OF Senna spectabilis, Rosmarinus officinalis AND Eugenia uniflora VEGETABLE ANTIBACTERIAL EXTRACTS AGAINST Pseudomonas aeruginosa ATCC 27853, Staphylococcus aureus ATCC 6538 AND Streptococcus pyogenes ATCC 19615 STANDARD STRAINS.

\begin{abstract}
The interest in alternative therapies and therapeutic use of plant extracts has been increasing in recent years, and has had great scientific advances regarding the chemical and pharmacological aspects. The World Health Organization (WHO) considers medicinal plants as important pharmaceutical care instruments. In order to determine the compared antibacterial activity between Senna spectabilis, Rosmarinus officinalis and Eugenia uniflora extracts against standard strains of Pseudomonas aeruginosa ATCC 27853, Staphylococcus aureus ATCC 6538 and Streptococcus pyogenes ATCC 19615, the leaves of E. uniflora, R.officinallis and S. spectabilis were collected in the medicinal plant garden of the State University of Maringa - UEM/PR, and strains were provided by University Paranaense - Unipar. The antibacterial activity was determined by broth microdilution plate technique using Alamar Blue Assay (MABA) growth revelant. The minimum inhibitory concentration (MIC) using R. officinalis, E. uniflora against the S. aureus ATCC strain revealed results of $125 \mu \mathrm{g} / \mathrm{mL}$, for $S$. spectabilis extracts, MIC was of $250 \mu \mathrm{g} / \mathrm{mL} ; S$. pyogenes resulted in a MIC of $125 \mu \mathrm{g} / \mathrm{mL}$ was admitted only for $R$. officinalis and S. spectabilis, E. uniflora results showed $500 \mu \mathrm{g} / \mathrm{mL}$, and for $P$. aeruginosa, MIC was greater than $500 \mu \mathrm{m} / \mathrm{mL}$ for the three extracts. The extracts are considered as promising when used against $S$. aureus and $S$. pyogenes, but not for $P$. aeruginosa. However, new alternatives are being sought for treating this gram-negative strain.
\end{abstract}

KEYWORDS: Antibacterial. Plant extracts. Resistance.

Introdução

O Brasil possui a maior biodiversidade do mundo, contando com um número estimado de mais de $20 \%$ do total de espécies do planeta (FARIAS et al., 1994, BRASIL, 2006; ALVES et al., 2008). A Organização Mundial da Saúde (OMS) considera plantas medicinais como importantes instrumentos da assistência farmacêutica. Destaca-se pela própria OMS que cerca de $70 \%$ a $90 \%$ da população dos países em vias de desenvolvimento dependem das plantas me- dicinais como ferramenta para o desenvolvimento da atenção primária à saúde (SIMÕES et al., 2000; BISWAS et al., 2002; CORDEIRO et al., 2006)

As plantas são ferramentas interessantes para o controle do desenvolvimento de resistência bacteriana, e a pesquisa de alternativas terapêuticas representa um dos grandes desafios para a saúde pública (SPELLBERG et al., 2004; ALVIANO; ALVIANO, 2009). A resistência deve-se a alterações genéticas em microrganismos, que codificam diferentes mecanismos bioquímicos e impede a ação das drogas,

${ }^{1}$ Docente do curso de farmácia da Universidade Paranaense- Unipar- Unidade de Paranavaí (vinicius@unipar.br). Endereço: Avenida Senador Souza Naves, 613- CEP:87.650.000. Centro - Cruzeiro do Sul - Pr.

${ }^{2}$ Acadêmicas do programa de iniciação científica (PIC) - curso de farmácia da Universidade Paranaense-Unipar- Unidade de Paranavaí. Endereço: Avenida Huberto Bruning, 360 CEP:87706-140. Paranavaí-Pr.

${ }^{3}$ Docente do curso de farmácia da Universidade Paranaense- Unipar- Unidade de Paranavaí (gustavomeireles@unipar.br). Endereço: Rua Santos Dumont, Apto 401 CEP: Zona 3 - Maringá - Pr. 
resultando na interferência na síntese de parede celular; inibição da síntese de proteína; destruição da parede celular e alterações na síntese do ácido nucléico (TENOVER, 2006; CHATTOPADHYAY et al., 2009).

Destacamos o estudo de Senna spectabilis, Rosmarinus officinalis e Eugenia uniflora. O gênero Senna é sinônimo de Cassia, pertence à família Leguminosae, no qual compreende mais de 300 espécies. No Brasil são encontradas na caatinga e no cerrado, também conhecida como cássia-do-nordeste, muitas espécies são usadas e cultivadas como plantas ornamentais por produzirem belas flores em zonas tropicais e subtropicais, reconhecida por suas atividades biológicas e propriedades farmacológicas. Espécies de Senna têm sido utilizadas na medicina como antigripal e para resfriados, como laxativo, atividade esta atribuída à presença de antraquinonas, purgante e outras atividades tem sido reportadas como antibacteriana, antifúngica e antioxidante (TOREY et al., 2010). Rosmarinus officinalis pertence à família Labiateae popularmente conhecido como alecrim, alecrim-de-horta e alecrim-de-cheiro (SILVA, et al., 1995). Planta pequena de porte arbustivo podendo chegar a $1,5 \mathrm{~m}$ de altura, possui folhas aromáticas ricas em óleo essencial, sendo nativa na região mediterrânea e cultivada em diferentes países de clima temperado (FARIAS et al., 1994; MATOS; LORENZI, 2002). Diversas atividades biológicas têm sido relatadas para esta planta como antioxidante, antiparasitária, antissépticas, estimulante da memória, antiespasmódico em cólica renal, disminorréia, alívio de desordens respiratórias e estimular o crescimento capilar (SVOBODA; DEANS, 1992; AL-SEREITA; ABU-AMERB; SENA, 1999).

Eugenia uniflora pertence à família Mirtaceae, conhecida popularmente como pitangueira. É nativa do Brasil pode ser encontrada também na Argentina, Paraguai e Uruguai, tendo assim a capacidade de se adaptar a diferentes tipos de clima e solo. Possui frutos comestíveis sendo ricos em vitamina C e pró-vitamina A (OLIVEIRA et al., 2006). Foram relatadas atividades para esta espécie como antidiarreico, antirreumática, anti-hipertensiva, anti-inflamatória, antioxidante e também utilizado em bronquites, tosses, febres, ansiedade, e verminoses (SCHAPOVAL et al., 1994 ALMEIDA et al., 1995, AURICCHIO; BUGNO; BARROS, 2007, CORREA et al., 2011, BRANDELLI et al., 2009).

O estudo realizado por Costa et al., (2013) com extrato hidroalcoolico de plantas medicinais com uso popular como E. uniflora, R. officinalis e S. spectabilis demonstraram atividade antimicrobiana, o que vem a corroborar com a pesquisa de atividade do presente estudo.

O objetivo do trabalho foi avaliar e comparar os extratos vegetais de $S$. spectabilis, $R$. officinalis e E. uniflora, frente a cepas de origem padrão, American Type Culture Colletion (ATCC) de Pseudomonas aeruginosa ATCC 27853, Staphylococcus aureus ATCC 6538 e Streptococcus pyogenes ATCC 19615.

\section{Material e Métodos}

\section{Coleta e preparo do material vegetal}

O material vegetal foi colhido entre os meses de Abril e Junho de 2015 no Horto de Plantas Medicinais da Universidade Estadual de Maringá - UEM. As folhas foram transferidas para sacos plásticos, transportadas até o laboratório de Microbiologia da Unipar (Paranavaí-Pr). O material vegetal foi imerso em solução de hipoclorito de sódio a $0,01 \%$ por tempo de $45 \mathrm{~min}$. A secagem foi realizada em estufa de ar circulante estufa a temperatura de $40^{\circ} \mathrm{C}$ por 72 horas. Após este período, material vegetal foi triturado em moinho elétrico e armazenado em frascos âmbar.

\section{Preparo do extrato vegetal}

Os extratos foram preparados utilizando $100 \mathrm{~g}$ de folhas secas trituradas para $1000 \mathrm{~mL}$ de solvente orgânico. Para obtenção do extrato, a massa recém-pesada foi transferida para o aparelho de turbólise e submetido à agitação por tempo de $10 \mathrm{~min}$. e descanso de $5 \mathrm{~min}$., este ciclo foi repetido por 3 vezes. Após a extração, o produto da turbólise foi filtrado, rotaevaporado e acondicionado em frasco âmbar até o momento de uso. Para produção dos extratos empregou-se álcool etílico 70\%, hexano (PA) e acetato de etila (PA).

\section{Cepa Padrão}

A cepa de origem padrão Pseudomonas aeruginosa ATCC 27853, Staphylococcus aureus ATCC 6538 e Streptococcus pyogenes ATCC 19615 Newprov ${ }^{\circledR}$ empregada neste estudo, foram adquiridas pela Universidade Paranaense-Unipar.

\section{Determinação da atividade antibacteriana}

Para determinação da Concentração Mínima Inibitória - CIM as cepas foram reativadas empregando Infusão Cérebro Coração-BHI, favorecendo o crescimento das cepas. Preparou-se uma suspensão bacilar com cada cepa adquirida, empregando solução fisiológica estéril $(\mathrm{NaCl} 9,0$ $\mathrm{g} / \mathrm{L}$ ), estabilidade e turbidez comparada a escala número 1 de Mac-Farland. A suspensão padrão foi analisada quanto ao crescimento e contagem em UFC/mL, apresentando crescimento normal do microrganismo quando semeado em Ágar Mueller - Hinton.

\section{Microdiluição em placa}

O experimento foi realizado em triplicata utilizando o método de microdiluição em microplaca contendo 96 poços, seguindo as recomendações padronizadas por Franzblau (1998) e adaptações segundo o Clinical and Laboratory Standards Institute (CLSI).

Para a realização da técnica de microdiluição pela metodologia do MABA (Microplate Alamar Blue Assay), foi utilizada placa estéril de 96 orifícios. Nas colunas 1 e 12 em linhas de $\mathrm{A}$ até $\mathrm{H}$ foram adicionados $200 \mu \mathrm{L}$ de água destilada estéril, perfazendo a necessidade de evitar provável evaporação dos compostos a serem testados (FRANZBLAU et al., 1998).

Nos orifícios presentes nas linhas de A até D da coluna 11 Adicionou-se $200 \mu \mathrm{L}$ de caldo Mueller-Hinton, enquanto que nos orifícios correspondentes de $\mathrm{E}$ a $\mathrm{H}$ da coluna 11 adicionou-se $100 \mu \mathrm{L}$ de caldo Mueller-Hinton. Nos orifícios correspondentes da linha A de colunas de 2 a 10 foi adicionado $150 \mu \mathrm{L}$ de meio caldo Mueller-Hinton e os de li- 
nha $\mathrm{B}$ a $\mathrm{H}$ referentes a coluna 2 a 10 , foram adicionados 100 $\mu \mathrm{L}$ de caldo Mueller-Hinton.

Acrescentaram-se os extratos a serem testados. Todos os extratos foram diluídos para que tivessem concentração inicial de $16.000 \mu \mathrm{g} / \mathrm{mL}$. A linha A e B da microplaca e colunas de 2 a 10, procedeu-se nova diluição e todos os extratos partiram da diluição de $4.000 \mu \mathrm{g} / \mathrm{ml}$ (linha A); 4.000 $\mu \mathrm{g} / \mathrm{mL}$ (linha B); $2.000 \mu \mathrm{g} / \mathrm{mL}$ (linha C); $1.000 \mu \mathrm{g} / \mathrm{mL}$ (linha D); $500 \mu \mathrm{g} / \mathrm{mL}$ (linha E); $250 \mu \mathrm{g} / \mathrm{mL}$ (linha F); $125 \mu \mathrm{g} / \mathrm{mL}$ (linha $\mathrm{G}) ; 62.5 \mu \mathrm{g} / \mathrm{mL}$ (linha $\mathrm{H}$ ).

Os orifícios de coluna 2 a 10 da linha A receberam $50 \mu \mathrm{L}$ da diluição de $16.000 \mu \mathrm{g} / \mathrm{ml}$. Os orifícios de linhas B referentes às colunas de 2 a 9 receberam $100 \mu \mathrm{L}$ de extrato e a coluna 10 a substância padrão (Ceftazidima $1 \mathrm{mg} / \mathrm{mL}$ ). Após a homogeneização da linha $\mathrm{B}$, procede à diluição de linha $\mathrm{B}$ a $\mathrm{H}$ de colunas de 2 a 10, ao final desprezar volume de $100 \mu \mathrm{L}$.

Adicionou-se a suspensão bacilar diluída 1:25 referente a escala n. 1 de MacFarland realizada após protocolo de obtenção da suspensão bacilar. Os orifícios de colunas de 2 a 10 e linhas de B a H receberam volume de $100 \mu \mathrm{L}$ de suspensão de bactérias, os orifícios das linhas $\mathrm{E}$ a $\mathrm{H}$, referentes à coluna 11 receberam $100 \mu \mathrm{L}$ da suspensão de bactérias, com o intuito de ser controle positivo.

As placas foram seladas com filme de polietileno e incubadas em estufa de crescimento aeróbio à temperatura de $37^{\circ} \mathrm{C}$, por período de $24 / 48$ horas de incubação os orifícios A -11 e E -11, receberam $25 \mu$ de solução reveladora de Alamar Blue na proporção 1:1 e solução de Tween 80 a 10\% para cada cepa. As placas foram assim reincubadas por 24 horas a $37^{\circ} \mathrm{C}$. A presença de cor rósea indica crescimento microbiano e a presença de coloração azul, indica ausência de crescimento microbiano, quando cores intermediárias, as placas foram reincubadas por mais 24 horas.

\section{Resultados}

A metodologia de microdiluição em placa, com a finalidade de avaliação antifúngica empregando revelador crescimento Alamar Blue Assay - MABA, como teste padrão ouro, os resultados obtidos foram comparados à técnica de macrodiluição. Os testes realizados foram avaliados em triplicata.

Tabela 1: Atividade antibacteriana frente à cepa padrão de $P$. aeruginosa ATCC 27853, empregando extratos de $S$. spectabilis produzido com solventes de diferentes polaridades.

\begin{tabular}{|c|c|c|c|c|}
\hline Microrganismo & Concentraçãoug/mL & Etanólico $70^{\circ} \mathrm{GL}$ & Acetato de etila & Hexano \\
\hline \multirow[t]{6}{*}{ Cepa padrão $P$. aeruginosa ATCC 27853} & 2000 & $\mathrm{C}+$ & C-- & $\mathrm{C}+$ \\
\hline & 1000 & $\mathrm{C}+$ & $\mathrm{C}--$ & $\mathrm{C}+$ \\
\hline & 500 & $\mathrm{C}+$ & $\mathrm{C}+$ & $\mathrm{C}+$ \\
\hline & 250 & $\mathrm{C}+$ & $\mathrm{C}+$ & $\mathrm{C}+$ \\
\hline & 125 & $\mathrm{C}+$ & $\mathrm{C}+$ & $\mathrm{C}+$ \\
\hline & 62,5 & $\mathrm{C}+$ & $\mathrm{C}+$ & $\mathrm{C}+$ \\
\hline
\end{tabular}

C+ crescimento normal frente ao extrato; C-- crescimento inibido quando exposto ao extrato.

Notoriamente, o gênero Pseudomonas e particularmente a espécie P. aeruginosa foi caracterizado como microrganismo resistente ao efeito de vários compostos antibacterianos, inclusive de extratos empregando diferentes solventes. Podendo ser explicado pelo fato destas bactérias apresentarem uma membrana mais externa, o que impede a entrada de várias moléculas com poder de inibição ou bactericida, assim como contêm enzimas, com a capacidade de quebrar substâncias estranhas introduzidas ao meio (DUFFY; POWER, 2001; HOLETZ et al., 2002; PESSINI et al., 2003).
A tabela 1 destacou muito bem este parâmetro, que se associa ao estudo de extratos contendo substâncias com diferentes polaridades e mesmo assim não foi diagnosticado CIM que corresponda interesse futuro, todos foram superiores a $500 \mu \mathrm{g} / \mathrm{mL}$, apenas para acetato de etila, fato que inviabiliza seu uso em extratos brutos. A cepa em estudo apresentou-se sensível quando exposta à concentração de $1 \mathrm{mg} / \mathrm{mL}$ de ceftazidima, medicamento empregado como droga controle.

Tabela 2: Atividade antibacteriana frente à cepa padrão de P. aeruginosa ATCC 27853, empregando extratos de R. officinalis produzido com solventes de diferentes polaridades.

\begin{tabular}{|c|c|c|c|c|}
\hline Microrganismo & Concentraçãoug/mL & Etanólico $70^{\circ} \mathrm{GL}$ & Acetato de etila & Hexano \\
\hline \multirow[t]{6}{*}{ Cepa padrão $P$. aeruginosa ATCC 27853} & 2000 & $\mathrm{C}+$ & $\mathrm{C}+$ & $\mathrm{C}+$ \\
\hline & 1000 & $\mathrm{C}+$ & $\mathrm{C}+$ & $\mathrm{C}+$ \\
\hline & 500 & $\mathrm{C}+$ & $\mathrm{C}+$ & $\mathrm{C}+$ \\
\hline & 250 & $\mathrm{C}+$ & $\mathrm{C}+$ & $\mathrm{C}+$ \\
\hline & 125 & $\mathrm{C}+$ & $\mathrm{C}+$ & $\mathrm{C}+$ \\
\hline & 62,5 & $\mathrm{C}+$ & $\mathrm{C}+$ & $\mathrm{C}+$ \\
\hline
\end{tabular}

$\mathrm{C}+$ crescimento normal frente ao extrato; $\mathrm{C}$-- crescimento inibido quando exposto ao extrato.

Destacou-se na tabela 2, efeito pronunciado de resistência da cepa de P. aeruginosa ATCC 27853, empregando extratos de diferentes polaridades e nenhuma resposta de
CIM, mesmo ao empregar concentrações superiores a 1000 $\mu \mathrm{g} / \mathrm{mL}$. 
Tabela 3: Atividade antibacteriana frente a cepa padrão de P. aeruginosa ATCC 27853, empregando extratos de E. uniflora produzido com agentes extratores de diferentes polaridades.

\begin{tabular}{ccccc}
\hline Microrganismo & Concentração $\boldsymbol{\mu g} / \boldsymbol{m L}$ & Etanólico $\mathbf{7 0 ^ { \circ }} \mathbf{G L}$ & Acetato de etila & Hexano \\
\hline Cepa padrão P. aeruginosa ATCC 27853 & 2000 & $\mathrm{C}+$ & $\mathrm{C}--$ & $\mathrm{C}+$ \\
& 1000 & $\mathrm{C}+$ & $\mathrm{C}+$ & $\mathrm{C}+$ \\
& 500 & $\mathrm{C}+$ & $\mathrm{C}+$ & $\mathrm{C}+$ \\
& 250 & $\mathrm{C}+$ & $\mathrm{C}+$ & $\mathrm{C}+$ \\
& 125 & $\mathrm{C}+$ & $\mathrm{C}+$ & $\mathrm{C}+$ \\
& 62,5 & $\mathrm{C}+$ & $\mathrm{C}+$ & $\mathrm{C}+$ \\
\hline
\end{tabular}

C+ crescimento normal frente ao extrato; C-- crescimento inibido quando exposto ao extrato.

$\mathrm{Na}$ tabela 3, destacou-se apenas um efeito discreto do extrato de E. uniflora frente a cepa padrão de P. aeruginosa
ATCC 27853, necessitando de $2000 \mu \mathrm{g} / \mathrm{mL}$, extrato de acetato de etila para exibir inibição microbiana.

Tabela 4: Atividade antibacteriana frente à cepa padrão de S. aureus ATCC 6538, empregando extratos de S. spectabilis produzido com solventes de diferentes polaridades.

\begin{tabular}{|c|c|c|c|c|}
\hline Microrganismo & Concentraçãoug/mL & Etanólico $70^{\circ} \mathrm{GL}$ & Acetato de etila & Hexano \\
\hline \multirow[t]{6}{*}{ Cepa padrão S. aureus ATCC 6538} & 2000 & $\mathrm{C}--$ & C-- & $\mathrm{C}+$ \\
\hline & 1000 & $\mathrm{C}--$ & $\mathrm{C}--$ & $\mathrm{C}+$ \\
\hline & 500 & $\mathrm{C}--$ & $\mathrm{C}--$ & $\mathrm{C}+$ \\
\hline & 250 & $\mathrm{C}--$ & C-- & $\mathrm{C}+$ \\
\hline & 125 & $\mathrm{C}+$ & $\mathrm{C}+$ & $\mathrm{C}+$ \\
\hline & 62,5 & $\mathrm{C}+$ & $\mathrm{C}+$ & $\mathrm{C}+$ \\
\hline
\end{tabular}

De acordo com a tabela 4 , o efeito pronunciado do extrato de S. spectabilis frente à cepa de S. aureus ATCC 6538 , para os extratos empregando-se álcool $70^{\circ} \mathrm{GL}$ e acetato de etila os efeitos de inibição foram mais evidentes, ambos apresentaram resposta na concentração de $250 \mu \mathrm{g} / \mathrm{mL}$.

Tabela 5: Atividade antibacteriana frente à cepa padrão de S. aureus ATCC 6538, empregando extratos de R. officinalis produzido com agentes extratores de diferentes polaridades.

\begin{tabular}{|c|c|c|c|c|}
\hline Microrganismo & Concentração $\mu \mathrm{g} / \mathrm{mL}$ & Etanólico $70^{\circ} \mathrm{GL}$ & Acetato de etila & Hexano \\
\hline \multirow[t]{6}{*}{ Cepa padrão S. aureus ATCC 6538} & 2000 & C-- & C-- & C-- \\
\hline & 1000 & C-- & C-- & C-- \\
\hline & 500 & C-- & C-- & C-- \\
\hline & 250 & $\mathrm{C}+$ & C-- & $\mathrm{C}+$ \\
\hline & 125 & $\mathrm{C}+$ & C-- & $\mathrm{C}+$ \\
\hline & 62,5 & $\mathrm{C}+$ & $\mathrm{C}+$ & $\mathrm{C}+$ \\
\hline
\end{tabular}

C+ crescimento normal frente ao extrato; C-- crescimento inibido quando exposto ao extrato.

Na análise da Tabela 5, verificou-se efeito pronunciado $R$. officinalis para os três extratos etanol, acetato de etila e hexano, sendo correspondente aos CIM's de 500, 125 e $500 \mu \mathrm{g} / \mathrm{mL}$ respectivamente. O extrato de acetato de etila demonstrou-se como mais eficaz neste caso.

Tabela 6: Atividade antibacteriana frente à cepa padrão de S.aureus ATCC 6538, empregando extratos de E. uniflora produzido com solventes de diferentes polaridades.

\begin{tabular}{|c|c|c|c|c|}
\hline Microrganismo & Concentraçãoug/mL & Etanólico $70^{\circ} \mathrm{GL}$ & Acetato de etila & Hexano \\
\hline \multirow[t]{6}{*}{ Cepa padrão S. aureus ATCC 6538} & 2000 & C-- & C-- & C-- \\
\hline & 1000 & $\mathrm{C}--$ & C-- & C-- \\
\hline & 500 & C-- & C-- & C-- \\
\hline & 250 & $\mathrm{C}--$ & C-- & C-- \\
\hline & 125 & $\mathrm{C}+$ & C-- & C-- \\
\hline & 62,5 & $\mathrm{C}+$ & $\mathrm{C}+$ & $\mathrm{C}+$ \\
\hline
\end{tabular}

$\mathrm{C}+$ crescimento normal frente ao extrato; $\mathrm{C}-$ - crescimento inibido quando exposto ao extrato 
Na tabela 6, evidenciou-se o efeito inibidor da cepa de $S$. aureus na concentração de $125 \mu \mathrm{g} / \mathrm{mL}$ para os extratos de acetato de etila e hexano. Para o extrato etanólico, a res- posta foi de $250 \mu \mathrm{g} / \mathrm{mL}$, como concentração capaz de provocar inibição.

Tabela 7: Atividade antibacteriana frente à cepa padrão de S. pyogenes ATCC 19615, empregando extratos de $S$. spectabilis produzido com solventes de diferentes polaridades.

\begin{tabular}{|c|c|c|c|c|}
\hline Microrganismo & Concentração $\mu \mathrm{g} / \mathrm{mL}$ & Etanólico $70^{\circ} \mathrm{GL}$ & Acetato de etila & Hexano \\
\hline \multirow[t]{6}{*}{ Cepa padrão S. pyogenes ATCC 19615} & 2000 & C-- & C-- & C-- \\
\hline & 1000 & C-- & C-- & C-- \\
\hline & 500 & C-- & C-- & C-- \\
\hline & 250 & $\mathrm{C}+$ & $\mathrm{C}+$ & $\mathrm{C}+$ \\
\hline & 125 & $\mathrm{C}+$ & $\mathrm{C}+$ & $\mathrm{C}+$ \\
\hline & 62,5 & $\mathrm{C}+$ & $\mathrm{C}+$ & $\mathrm{C}+$ \\
\hline
\end{tabular}

$\mathrm{C}+$ crescimento normal frente ao extrato; $\mathrm{C}--$ crescimento inibido quando exposto ao extrato.

Na tabela 7 evidenciou-se efeito inibidor da cepa de S. pyogenes para os três extratos testados na concentração de $500 \mu \mathrm{g} / \mathrm{mL}$, resultado com efeito discreto, onde se sabe que o ideal é apresentar inibição inferior a $250 \mu \mathrm{g} / \mathrm{mL}$ para considerar como efeito pronunciado (FRANZBLAU et al., 1998; HOLETZ et al., 2002).

Tabela 8: Atividade antibacteriana frente à cepa padrão de $S$. pyogenes ATCC 19615, empregando extratos de $R$. officinalis produzido com solventes de diferentes polaridades.

\begin{tabular}{|c|c|c|c|c|}
\hline Microrganismo & Concentraçãopg/mL & Etanólico $70^{\circ} \mathrm{GL}$ & Acetato de etila & Hexano \\
\hline \multirow[t]{6}{*}{ Cepa padrão S. pyogenes ATCC 19615} & 2000 & $\mathrm{C}--$ & C-- & C-- \\
\hline & 1000 & $\mathrm{C}--$ & C-- & $\mathrm{C}--$ \\
\hline & 500 & $\mathrm{C}+$ & C-- & $\mathrm{C}+$ \\
\hline & 250 & $\mathrm{C}+$ & C-- & $\mathrm{C}+$ \\
\hline & 125 & $\mathrm{C}+$ & $\mathrm{C}+$ & $\mathrm{C}+$ \\
\hline & 62,5 & $\mathrm{C}+$ & $\mathrm{C}+$ & $\mathrm{C}+$ \\
\hline
\end{tabular}

$\mathrm{C}+$ crescimento normal frente ao extrato; $\mathrm{C}$-- crescimento inibido quando exposto ao extrato.

De acordo com a tabela 8 , observou-se um efeito pronunciado de inibição com CIM $250 \mu \mathrm{g} / \mathrm{mL}$ para o extrato de etila, caracterizando-se como potencial fonte para futuros estudos mais na avaliação de outras atividades com microrganismos.

Tabela 9: Atividade antibacteriana frente à cepa padrão de S. pyogenes ATCC 19615, empregando extratos de E. uniflora produzido com solventes de diferentes polaridades.

\begin{tabular}{|c|c|c|c|c|}
\hline Microrganismo & Concentraçãopg/mL & Etanólico $70^{\circ} \mathrm{GL}$ & Acetato de etila & Hexano \\
\hline \multirow[t]{6}{*}{ Cepa padrão S. pyogenes ATCC 19615} & 2000 & C-- & C-- & C-- \\
\hline & 1000 & C-- & C-- & C-- \\
\hline & 500 & $\mathrm{C}+$ & C-- & $\mathrm{C}+$ \\
\hline & 250 & $\mathrm{C}+$ & $\mathrm{C}--$ & $\mathrm{C}+$ \\
\hline & 125 & $\mathrm{C}+$ & $\mathrm{C}--$ & $\mathrm{C}+$ \\
\hline & 62,5 & $\mathrm{C}+$ & $\mathrm{C}+$ & $\mathrm{C}+$ \\
\hline
\end{tabular}

$\mathrm{C}+$ crescimento normal frente ao extrato; $\mathrm{C}$-- crescimento inibido quando exposto ao extrato

Na tabela 9 podem-se destacar os resultados de inibição ao S. pyogenes ATCC 19615 empregando a concentração de $125 \mu \mathrm{g} / \mathrm{mL}$ do extrato de E. uniflora, quando produzido com o solvente acetato de etila.

\section{Discussão}

O interesse por terapias alternativas e o uso terapêutico de produtos naturais tem crescido nos últimos anos, principalmente devido à medicina convencional ser ineficiente em alguns casos, ao uso incorreto e/ou abusivo, sendo que um grande número da população mundial não tem acesso ao tratamento. Este interesse está principalmente em derivados de plantas medicinais, onde se obteve um grande avanço científico, envolvendo estudos químicos e farmacológicos visando obter novas entidades químicas com propriedades farmacêuticas, sendo demonstrado pelo grande número de trabalhos publicados na área (CECHINEL FILHO; YUNES 1998).

No estudo realizado por Auricchio; Bugno; Barros (2007), foi relatado que extratos hidroalcoólicos de folhas de E. uniflora possui atividade antimicrobiana frente a $S$. aureus com CIM de $80 \mu \mathrm{g} / \mathrm{mL}$, atividade pode ser atribuída a composto fenólicos presente nas folhas como taninos e glicoside- 
os de flavonoídes e óleo volátil, sendo os principais responsáveis pela atividade da planta. No presente estudo realizada com a mesma planta encontrou-se atividade parecida, porém no extrato hexânico com CIM de $125 \mu \mathrm{g} / \mathrm{mL}$. Pessini et al., (2003) realizaram estudo com extratos de diferentes plantas utilizadas na medicina popular brasileira e verificaram que a espécie E. uniflora possui boa atividade antifúngica. Algumas plantas medicinais possuem alguns metabólitos como terpenos oxigenados, taninos, aldeídos e glicosídeos cardíacos, uma vez que a estes compostos podem ser atribuído à atividade antimicrobiana (BERTINI et al., 2005).

A melhor atividade obtida com $R$. Officinalis foi com extrato acetato de etila frente ao microrganismo $S$. aureus que pode ser explicado pela hidrofobicidade dos extratos graxosos e óleos essenciais, o que torna mais permeável facilitando a penetração em compostos lipídicos na membrana celular de Gram-positivos, causando maior morte celular (DENYER; HUGO, 1991). Estudo realizado por Hussain et al., (2010) o óleo essencial de alecrim possui boa atividade antimicrobiana sendo comparado ao controle ciprofloxacino. A atividade antimicrobiana do óleo essencial pode ser atribuída aos compostos $\alpha$-pineno, cânfora, verbenona e borneol, sendo este o mais potente (SANTOYO et al., 2005). Correa Junior; Ming; Schefer, (1991) relata que alguns fatores realcionados ao cultivo (tipo de solo, luz, umidade etc.) época da colheita pode interferir na composição química da planta e também na sua atividade.

$\mathrm{Na}$ busca por novas alternativas terapêuticas, as plantas, por sintetizarem substâncias com atividade antibacteriana, como compostos fenólicos, taninos, terpenos, cumarinas, isoflavonóides, glicosídeos e substâncias oleosas (YUNES; PEDROSA; CECHINEL FILHO, 1998; NASCIMENTO et al., 2000), passaram a despertar o interesse da indústria farmacêutica. Alguns estudos relataram atividade antibacteriana de extratos de Azadirachta indica frente a cepas da espécie Streptococcus sp. No estudo realizado por Subramanian et al., (2005), extratos produzidos a partir de folhas da planta demonstraram tal atividade contra $S$. mutans presentes na cavidade oral de humanos. Chattopadhyay et al., (2009) em seu estudo destacou forte atividade inibitória contra $S$. aureus dos extratos aquosos e etanólicos produzidos através das folhas de $A$. indica. Alves et al., (2008) verificou em seu estudo atividade antibacteriana dos extratos de $A$. indica contra cepas S. aureus, Bacillus subtilis, Aspergillus niger e Escherichia coli. No estudo realizado por Subramanian et al., (2005), extratos produzidos a partir de folhas desta planta demonstraram tal atividade contra $S$. mutans presentes na cavidade oral de humanos.

Cepas de $P$. aeruginosa isoladas em hospitais são marcadas inúmeras vezes por multirresistência, o paciente oriundo de UTI - Unidade de terapia intensiva tende a apresentar maior número de isolados. Os medicamentos como ciprofloxacina, imipenem, ceftazidima e piperacilina, são os mais citados pela literatura como suscetíveis ao microrganismo em desenvolver resistência em UTI. Os mecanismos de resistência desenvolvidos pelo microrganismo estão associados à modificação ou inativação do antimicrobiano, diminuição da permeabilidade celular e bomba de efluxo (KONEMAN et al., 2001; SOARES, 2005; FERREIRA; LALA, 2010; ALMEIDA et al;2012).

Sabe-se que existe diferenças entre sensibilidade de cepas de $P$. aeruginosa $s p$, $S$. aureus e $S$. pyogenes, os testes justificam essas informações, cada microrganismo em estudo apresenta suas peculiaridades relacionadas a formação e constituição de parede celular, mecanismos de patogenicidade e desenvolvimento de resistência. No entanto, ao comparar-se $P$. aeruginosa com os demais, fica clara sua predominância em sobreviver na vigência de concentrações distintas dos extratos empregados neste trabalho.

Para os testes empregando $S$. spectabilis, o melhor efeito pronunciado foi de quando expostos ao $S$. aureus ATCC 6538, extrato hidroalcoolico e também nos estudos de acetato de etila com CIM de $250 \mu \mathrm{g} / \mathrm{mL}$. De acordo com Krishnan et al., (2010) que analisaram a atividade antimicrobiana do extrato de folhas de Senna spectabilis, utilizando solventes de diferentes polaridades, verificaram que os extratos metanólicos e acetona obtiveram os melhores resultados de inibição frente a bactérias e fungos, comparados com os extratos de baixa polaridade, hexano, diclorometano e acetato de etila.

\section{Conclusão}

Conclui-se que o extrato de acetato de etila e hexânico de $R$. officinalis e E. uniflora respectivamente, foram ativos para $S$. aureus com concentração efetiva semelhantes de $125 \mu \mathrm{g} / \mathrm{mL}$. O extrato de acetato de etila de E. uniflora foi ativo frente ao microrganismo $S$. pyogenes com CIM de $250 \mu \mathrm{g} / \mathrm{mL}$. Frente à bactéria Gram-negativa $P$. aeruginosa nenhum dos extratos do presente trabalho demonstraram-se efetivos. Com o intuito de promover alternativas terapêuticas e diminuir efeitos colaterais, outros estudos deverão ser realizados com S. spectabilis, E. uniflora e R. officinalis.

\section{Referências}

AL-SEREITA, M. R.; ABU-AMERB, K. M.; SENA, $P$. Farmacólogo of Rosemary (Rosmarinus officinalis Linn.) and its therapeutic potentials. Indian Journal of Experimental Biology. v. 1, n. 37, pp. 124-131, 1999.

ALMEIDA, C. E. et al. Analysis of antidiarrhoeic effect of plants used in popular medicine. Rev. de Saude Publica, São Paulo, v. 29, n. 6, p. 428-433, 1995.

ALMEIDA, M. G. C. et al. Perfil de sensibilidade a antimicrobianos em Pseudomonas aeruginosa de origem hospitalar e ambulatorial oriundas de laboratórios público e privado, em Belém, estado do Pará. Revista Bras. Análises Clínicas, 44(1), 44-49, 2012.

ALVES, E. G. et al. Avaliação da atividade antibacteriana de extratos brutos de Miconia fallax pelo método da microdiluição em caldo. Revista da Sociedade de Química, FURB, Novembro de 2008.

ALVIANO, D. S.; ALVIANO, C. S. Plant extracts: search for new alternatives to treat microbial diseases. Current Pharmaceutical Biotechnology. v. 10. p. 106-121, 2009.

AURICCHIO, M. T.; BUGNO, A.; BARROS, S. B. M. Antimicrobial and antioxidant activities and toxicity of 
Eugenia unifora. Latin American Journal of Pharmacy, v. 26, n. 1, p. $76-81,2007$.

BERTINI, L. M. et al. Perfil de sensibilidade de bactérias frente a óleos essenciais de algumas plantas do nordeste do Brasil. Infarma, v. 17, nº 3/4, 2005.

BISWAS, K. et al. Biological activites and medicinal properties of neem (Azadirachta indica). Current Science, V. 82, N. 11, 1336-1345, 2002.

BRANDELLI, C. L. C. et al. Indigenous traditional medicine: in vitro anti-giardial activity of plants used in the treatment of diarrhea. Parasitology Research, Kansas, v. 104, n. 6, p. 1345-1349, 2009.

BRASIL. Ministério da Saúde. Secretaria de Ciência Tecnologia e Insumos Estratégicos. Departamento de Assistência Farmacêutica. A fitoterapia no SUS e o Programa de Pesquisas de Plantas Medicinais da Central de Medicamentos. Brasília: Ministério da Saúde, 2006. 148 p. (Série B. Textos Básicos de Saúde).

CECHINEL FILHO, V.; YUNES, R. A. Estratégias para a obtenção de compostos farmacologicamente ativos a partir de plantas medicinais. Conceitos sobre modificação estrutural para otimização da atividade. Quim. Nova, v. 21, n. 1, p- $99-105,1998$.

CHATTOPADHYAY, R. R. et al. A avaliação comparativa do potencial antibacteriano de algumas plantas utilizadas na medicina tradicional indiana para o tratamento de infecções microbianas. Braz. arco. biol. Tecnologia, v. 52, n. 5, p. 1123-1128, 2009.

CORDEIRO, C. H. G. et al. Análise Farmacognóstica e atividade antibacteriana de extratos vegetais empregados em formulação para a higiene bucal. Revista Bras. Ciências Farmac, v. 42, n. 3, p. 395-404, 2006.

CORREA JUNIOR, C.; MING, L. C.; SCHEFER, M. C. Cultivo de plantas medicinais, condimentares aromáticas. Curitiba: Copiright Emater-Parana, 80p. 1991.

CORREA, H. A. M. et al. Extracts from pitanga (Eugenia uniflora L.) leaves: Influence of extraction process on antioxidant properties and yield of phenolic compounds. Journal of Supercritical Fluids, v. 55, n. 3, p. 998-1006, 2011.

COSTA, G. M. Avaliação da atividade antimicrobiana de plantas medicinais. Dissertação de mestrado - UEM/2013/ Maringá. 73 fl. 2013.

DENYER, S. P.; HUGO, W. B. Biocide-induced damage to the bacterial cytoplasmic membrane. In S. P. Denyer, \& W. B. Hugo (Eds.), Mechanisms of action of chemical biocides (pp. 171-188). The Society for Applied Bacteriology, Blackwell Scientific Publication, Technical Series 27, Oxford, London. 1991.
DUFFY, C. F.; POWER, R. F. Antioxidant and antimicrobial properties of some Chinese plants extracts. Int $\mathbf{J}$ of Antimicro Agents. v. 17, p. 527-529, 2001.

FARIAS, M. R. et al. Espécies vegetais empregadas na produção de fitoterápicos em Santa Catarina. In: Simpósio de plantas Medicinais do Brasil, 12, 1994. Fortaleza. Anais. Fortaleza, 1994, p. 125.

FERREIRA, H; LALA, E. R. P. Pseudomonas aeruginosa: Um alerta aos profissionais de saúde. Revista Panamericana de Saúde, 12 (2), 44-50, 2010.

FRANZBLAU, S. G. et al. Rapid, low-technologiy MIC determination with clinical Mycobacterium tuberculosis isolates by using the Microplate Alamar Blue Assay. J. Clin. Microbiol. v. 32, n. 2, p. 362-366, 1998.

HOLETZ, F. B. et al. Screening of some plants used in the Brazilian folk medicine for the treatment of infectious diseases. Mem. do Inst. Oswaldo Cruz, Rio de Janeiro, v. 97, n. 7, p. 1027-1031, 2002.

HUSSAIN, A. I. et al. Rosmarinus officinalis essential oil: antiproliferative, antioxidant and antibacterial activities.

Braz. J. Microb. v. 41. p. 1070-1078. 2010

KRISHNAN, N. et al. Antimicrobial activity evaluation of Cassia spectabilis leaf extracts. International J. of Pharmacology. v. 6, n. 4, p. 510-514, 2010.

KONEMAN, E. et. al. Diagnóstico microbiológico. 5 ed. Rio de Janeiro: Guanabara Koogan, 2001.

MATOS, F. J. A.; LORENZI, H. Plantas medicinais no Brasil: Nativas e exóticas. Nova Odessa - SP, Instituto Plantarum de estudos da flora LTDA, 1ed. 261p. 2002.

NASCIMENTO, G. G. H. et. Al. Antibacterial activity of plant extracts and phytochemicals on antibiotic cresistant bacteria. Braz. Jour. of Microb. v. 31, p. 247-256, 2000.

OLIVEIRA, A. L. et al. Volatile compounds from pitanga fruit (Eugenia uniflora L.). Food Chemistry, v. 99, n. 1, p. $1-5,2006$.

PESSINI, G. L. et al. Avaliação da atividade antiobacteriana e antifúngica de extratos de plantas utilizadas na medicina popular. Revista Brasileira de Farmacognosia 13 (supl 1): 21-24; 2003

SANTOYO, S. et al. Chemical composition and antimicrobial activity of Rosmarinus officinalis L. essential oil obtained via supercritical fluid extraction. J. of Food Protection. v. 68, n. 4. p. 790-795, 2005.

SCHAPOVAL, E. E. S. et al. Evaluation of some pharmacological activities of Eugenia uniflora L. Journal of Ethnopharmacology, Limerick, v. 44, n. 3, p. 137-142, 1994. 
SCHENKEL, E. P.; GOSMANN, G.; PETROVICK,

P. R. Produtos de origem vegetal e o desenvolvimento de medicamentos. Farmacognosia da planta ao

medicamento. 3 ed. Porto Alegre: Editora da UFRGS, cap. 15, p. 301-332, 2001.

SILVA, I. et al. Noções sobre o organismo humano e utilização de plantas medicinais. Cascavel: Assoeste, 1995, 93.

SIMÕES, M. O. et al. Farmacognosia: da planta ao medicamento. Porto Alegre/Florianópolis: 2 ed/editora UFRGS/UFSC, 2000.

SPELLBERG, B. et al. Trends in antimicrobial drug development : Implications for the future. Antimicrobial Research and development. v. 38, 2004.

SOARES, M. C. S. T. Estudo da resistência aos antimicrobianos em amostras Pseudomonas aeruginosa isoladas em hospitais da cidade de Niterói - Rj.

DISSERTAÇÃO DE MESTRADO, NITERÓI-RJ, 2005.

SVOBODA, K. P.; DEANS, S. G. A study of the variability of Rosemary and sage and their volatile oils on the British market: their antioxidative propertes. Flavour and

Fragance journal, v. 7, p. 81-87, 1992.

TENOVER, F. C. Mechanisms of antimicrobial resistance in bacteria. Am. J. Med. v. 119 (Suppl. 1), p. S3-S10, 2006.

TOREY, A. et al. Standardization of Cassia spectabilis with Respect to Authenticity, Assay and Chemical Constituent Analysis. Molecules. v. 15, p. 3411-3420, 2010.

YUNES, R. A.; PEDROSA, R. C.; CECHINEL FILHO, V. Fármacos e fitoterápicos: a necessidade do desenvolvimento da indústria de fitoterápicos e fitofármacos no Brasil. Quím. Nova, São Paulo, v. 24, n. 1, p. 147-152, 2001.

Recebido em: 24/03/2016 Aceito em: 23/11/2016 